\title{
India Ink Staining Method
}

National Cancer Institute

\section{Source}

National Cancer Institute. India Ink Staining Method. NCI Thesaurus. Code C85642.

A microscopy staining method that utilizes India Ink, a water soluble carbon-based black ink, to determine the presence of microorganisms that are surrounded by a gelatinous capsule. This is a negative staining method in which background is stained in black and the microbes and microscopic structures of interest remain white. 